\title{
Red Blood Cell Flow in the Fetal Scalp during Hypoxemia in the Chronic Sheep Experiment: A Laser Doppler Flow Study
}

\author{
T. M. SMITS, J. G. AARNOUDSE, AND W. G. ZIJLSTRA \\ Department of Obstetrics and Gynecology, University Hospital, Groningen [T.M.S., J.G.A.] and Department of \\ Physiology, University of Groningen, Groningen, The Netherlands [W.G.Z.]
}

\begin{abstract}
Reliable monitoring of arterial blood gas values in the fetal scalp microcirculation requires an unimpaired local skin blood flow. Previous studies have shown that in the fetus blood flow to "nonvital" organs and tissues is reduced during hypoxemia. However, data on fetal scalp blood flow during hypoxemia have not been reported. Therefore, the influence of hypoxemia on scalp blood flow was studied in four chronically catheterized fetal lambs of 125-135 days of gestation. Red blood cell flow in the fetal scalp was continuously measured by the laser Doppler method during nine experiments. Reducing the oxygen saturation of fetal carotid arterial blood from an average control value of 52 to $21 \%$ for 20 min resulted in an average decrease of the laser Doppler flow index of $7 \%$. In vitro studies revealed that more than half of the observed decrease in laser Doppler flow index could be attributed to enhanced absorption of light from the $\mathrm{HeNe}$ laser caused by the deoxygenation of oxyhemoglobin itself. In the first 20 min after hypoxia, fetal scalp blood flow remained below the prehypoxic value. It is concluded that moderate hypoxemia causes only a small decrease in fetal scalp blood flow, certainly when compared to the dramatic fall in scalp blood flow that has been observed when local or circular pressure is exerted onto the fetal scalp. (Pediatr Res 20: 407-410, 1986)
\end{abstract}

\section{Abbreviations}

\author{
LDF, laser Doppler flow \\ $\mathrm{Po}_{2}$, oxygen tension \\ $\mathrm{So}_{2}$, oxygen saturation \\ EMG, electromyogram
}

\footnotetext{
Previous studies in the chronically catheterized fetal lamb have shown that hypoxemia causes a redistribution of blood flow to various organs (1-3). Blood flow to "vital" organs such as the brain, the adrenals, and the heart is increased, whereas a marked reduction is found in blood flow to the carcass (muscle, bone, and skin tissue). Data on fetal scalp blood flow during hypoxemia in the chronic sheep experiment have not been reported so far. This lack of information on fetal scalp blood flow is surprising, as the microvascular bed of the fetal scalp is widely used for blood gas measurement in the human fetus during labor. If hypoxemia really causes a significant reduction in scalp blood

Received April 18, 1985; accepted December 30, 1985.

Requests for reprints should be addressed to Dr. J. G. Aarnoudse, Department of Obstetrics and Gynecology, University Hospital, Oostersingel 59, 9713 EZ Groningen. The Netherlands.

Supported by the Jan Kornelis de Cock Stichting.
}

flow, as it does in the carcass as a whole, then local skin metabolism will have a profound effect on blood gas values in the microvasculature of the fetal scalp, resulting in a discrepancy between the carotid arterial and scalp blood gas values under these circumstances (4).

In most studies on tissue or organ blood flow in the fetus, radiolabeled microspheres have been used. The advantages and limitations of the microsphere method have been extensively reviewed $(3,5,6)$. Two of the most obvious limitations are that it gives flow data on a single point in time only and that the method cannot be used in the human.

These restrictions do not apply to a recently developed method for microvascular blood flow measurement, the laser Doppler technique (7-12). With this technique, the Doppler shift of monochromatic laser light scattered back by moving red blood cells in the microvascular bed of a tissue is used to determine an index of flow. This flow index is a relative but linear measure of tissue blood flow $(7,9,12-15)$.

In previous studies we have shown that the laser Doppler method can be used to measure changes in fetal scalp blood flow in the human during labor (9) and in the acute fetal sheep experiment (16). The aim of the present study was to investigate the changes in red blood cell flow in the microvascular bed of the fetal scalp during hypoxemia in the chronically catheterized sheep fetus, using the laser Doppler technique.

\section{METHODS}

Animal preparation. Four pregnant healthy white ewes (Texel breed) with a gestational age of 120 to 125 days at the day of surgery were used for this study. The surgical procedure was carried out under general anesthesia with ketamine $(0.1 \mathrm{mg} / \mathrm{kg} /$ $\mathrm{min}$ ), while the ewe was ventilated through an endotracheal tube with a $\mathrm{N}_{2} \mathrm{O} / \mathrm{O}_{2}$ gas mixture to which $0.5 \%$ fluothane was added. A maternal femoral artery and vein were cannulated to obtain blood samples during the surgical procedure and during the experiments. After laparotomy the fetal head was delivered by a small uterine incision. Catheters (Norton S.A.; Tygon tubing, outer diameter: $1.9 \mathrm{~mm}$, internal diameter: $1.0 \mathrm{~mm}$ ) were placed in the right carotid artery and jugular vein and in the trachea of the fetus. Teflon-insulated stainless steel wires (Cooner Wire Company; AS 633) were placed around one of the eyes, in the long nuchal muscles, on the thorax and in the uterine wall to record the electrooculogram, nuchal EMG, fetal heart rate, and uterine EMG, respectively. The LDF probe, a small plastic disk, was glued to the shaved skin of the fetal scalp with cyanoacrylate adhesive (Loctite 416).

After repositioning the fetal head, the lost amount of amniotic fluid was replaced by a warm isotonic saline solution and a catheter was left in the amniotic cavity to measure intrauterine pressure. The uterine and abdominal walls were carefully closed 
and the catheters, electrode wires, and optical fibers of the LDF probe were led through a subcutaneous tunnel to the maternal flank, where they emerged from a small skin incision. The ewe was allowed to recover for at least 3 days. Catheters were continuously flushed with a heparinized isotonic saline solution by means of infusion pumps. Antibiotics (Cefuroxim and Amikacine) were given for 5 days, beginning on the day of surgery.

The laser Doppler instrument. Monochromatic light $(\lambda=632.8$ $\mathrm{nm}$ ) from a Helium Neon laser (Spectra Physics Inc; S105) is transported to the scalp by a monofilament optical fiber (Quartz \& Silice; QSF 300). The light scattered back from the fetal scalp is guided to a low noise silicon photodiode (EG\&G ElectroOptics; HUV $1100 \mathrm{BQ}$ ) by a second optical fiber. The resulting electrical signal is fed into an analog processor which calculates a flow index as previously described (9). The flow index is a relative measure of microvascular red blood cell flow. The incident laser light is randomly scattered in skin tissue, thus eliminating the direction sensitivity of the Doppler method (7). The flow dependent signal is derived from a depth of approximately 1 to $1.5 \mathrm{~mm}$ in skin tissue $(7,13,14)$.

It is important that the same part of the microvascular bed is illuminated throughout the whole experiment. For this reason a relatively large flow probe was designed to fix the optic fibers to the fetal scalp. The flow probe, which has a diameter of $25 \mathrm{~mm}$ and a height of $5 \mathrm{~mm}$, is constructed in such a way that the distance between the fibers at the skin surface is approximately $0.5 \mathrm{~mm}$. To prevent local pressure of the flow probe on the underlying skin, the relatively stiff glass fibers emerge from the flow probe parallel to the scalp surface in the direction of the fetal back.

Before each experiment, the noise compensation of the laser Doppler instrument was adjusted by means of a static scatterer which yielded the same reflected light intensity as the fetal scalp under study. The direct influence of changes in hemoglobin oxygen saturation on the laser Doppler signal was studied by application of the flow probe to a microcirculatory model consisting of 15 channels of $100 \mu \mathrm{m}$ diameter in opaque material. With an infusion pump, red blood cells were aspirated from a tonometer cuvette (Instrumentation Laboratory; IL 237) at constant flow rate. Reducing the oxygen saturation of the hemoglobin from 50 to $20 \%$ resulted in an average decrease in the laser Doppler flow index of $4.8 \%$.

Experimental procedure. For $1 \mathrm{wk}$ before the surgical procedure, the ewe was trained daily to accept the face mask necessary for the administration of the hypoxic gas mixture. The experiments were carried out 3 to 11 days after the surgical procedure. Fetal electrical activities (electrooculogram, nuchal EMG, uterine EMG, fetal heart rate), LDF, intrauterine pressure, and tracheal pressure were recorded on a polygraph (Hewlett Packard; HP $7758 \mathrm{~A}$ ) at a paper speed of $5 \mathrm{~mm} / \mathrm{min}$.

The experiment started with the ewe breathing room air by means of the face mask. After a control period of $20 \mathrm{~min}$, the room air was replaced by a gas mixture containing $10 \% \mathrm{O}_{2}$ and $4 \% \mathrm{CO}_{2}$. Carbon-dioxide was added to the inspiratory gas mixture to antagonize the $\mathrm{PCO}_{2}$ decrease in the maternal arterial blood resulting from the maternal hypoxic ventilatory drive. Hypoxia was maintained for $20 \mathrm{~min}$, after which the ewe was allowed to breathe room air again by means of the face mask for $20 \mathrm{~min}$.

Arterial blood samples from fetus and mother were taken at 10 -min intervals from $20 \mathrm{~min}$ before to $20 \mathrm{~min}$ after the experimental procedure. The blood samples were immediately measured on an automatic blood gas analyzer (Radiometer; ABL-2) and an oximeter also providing the total hemoglobin concentration (Radiometer; OSM-2).

On each animal at least two experiments were done and one animal was used three times. For these experiments, only animals with resting fetal arterial $\mathrm{pH}$ and $\mathrm{SO}_{2}$ values exceeding 7.25 and $40 \%$, respectively, were included. After every experiment the ewe was allowed to rest for at least $24 \mathrm{~h}$. In three experiments, fetal arterial $\mathrm{PO}_{2}$ and $\mathrm{SO}_{2}$ were measured continuously: a small external flow-through cuvette was connected to the catheters in the carotid artery and jugular vein and the measurements were carried out by means of a Clark type oxygen electrode (AVLMesstechnik) and a fiber optic oximeter (Schwartzer; IVH3) as previously described (4). Fetal arterial blood pressure was measured continuously in three experiments.

Afterward, the laser Doppler tracings were sampled at a rate of $5 / \mathrm{min}$ and the data was fed into a microcomputer (Apple Comp. Inc; Apple Europlus) to calculate the mean and SDs of the LDF index for each period of $20 \mathrm{~min}$. The variability of the LDF signal occurring during the various phases of the experiment was determined. To this end we calculated the square root of the mean of the squared differences between the original LDF signal and the averaged signal, obtained by using a moving window of $84 \mathrm{~s}$. This value was then expressed as a percentage of the mean LDF value (Table 1, LDF variability). For statistical analysis, Student's $t$ test for paired and unpaired samples was used. As a level of significance, a $p$ value of 0.05 was chosen.

\section{RESULTS}

For this study the results of nine experiments on four healthy fetal lambs at 125-135 days of gestation were used. In Table 1 the effects of maternal hypoxia on fetal carotid arterial blood $\mathrm{pH}$ and gas tensions are shown. Fetal $\mathrm{SO}_{2}$ fell from an average of 52 to $21 \%$ when the breath intake of the ewe was changed from room air to the hypoxic gas mixture. $\mathrm{PO}_{2}$ decreased from an average of 20 to $11 \mathrm{~mm} \mathrm{Hg}$, whereas $\mathrm{PCO}_{2}$ and $\mathrm{pH}$ showed no significant change. During hypoxia, an average increase in hemoglobin concentration of $1.2 \mathrm{~g} / \mathrm{dl}$ was observed. Maternal hypoxia resulted in an increase in fetal mean arterial blood pressure and pulse pressure, ranging from 6 to $15 \mathrm{~mm} \mathrm{Hg}$ and 18 to $20 \mathrm{~mm}$ $\mathrm{Hg}$, respectively. Fetal heart rate decreased with 30 to $100 \mathrm{bpm}$, to values ranging from 80 to $140 \mathrm{bpm}$.

Figure 1 shows an example of an experiment where fetal scalp blood flow and fetal carotid arterial $\mathrm{PO}_{2}$ and $\mathrm{SO}_{2}$ were measured continuously, before, during, and after hypoxemia. In all experiments, the decrease in LDF index was small in comparison to the spontaneous variations in fetal scalp blood flow.

The effect of hypoxemia on the LDF index in all nine experiments is summarized in Table 1 . In all experiments there was a statistically significant reduction of the LDF index during hypoxia, on average $6.9 \%$ (range 2.9 to $10.4 \%$ ) in comparison with the period prior to hypoxia. The time course of the changes in LDF shortly after the beginning of hypoxia was analyzed by calculating the mean value of the LDF index in subsequent periods of $5 \mathrm{~min}$ for each experiment. It appeared that in six experiments there was a more or less continuous decrease in the LDF index during hypoxia, whereas in the remaining three experiments the LDF index fell rapidly after the onset of hypoxia, whereafter it tended to stabilize. The reduction in LDF index during hypoxia is partly due to attenuation of the LDF signal caused by the increased absorptivity of deoxygenated hemoglobin at the wavelength of the light produced by the Helium Neon laser $(632.8 \mathrm{~nm})$ as described above. No systematic difference was observed between the results of the first and second experiment in the same animal.

Changing from $10 \% \mathrm{O}_{2}$ to room air resulted in far less consistent changes in laser Doppler blood flow. As compared to the period of hypoxia, the LDF index increased in four experiments, decreased in three, and in one experiment no statistically significant change occurred. In the first $20 \mathrm{~min}$ after hypoxia, the LDF signal was still $7.5 \%$ (range 0.7 to $19.3 \%$ ) below the prehypoxic value. Also during the second 20 -min period the LDF index had not yet returned to the prehypoxic value, while the oxygen saturation had largely recovered but the $\mathrm{pH}$ had a tendency to decrease. In five experiments the LDF value was still below the prehypoxic value, whereas in one experiment an increase in LDF index was observed, only in one experiment the LDF value had 
Table 1. Arterial pH and blood gas values and laser Doppler scalp blood flow of nine experiments in four fetal lambs

\begin{tabular}{|c|c|c|c|c|c|c|c|}
\hline $\begin{array}{c}\text { Period } \\
(20 \text { min each })\end{array}$ & $\mathrm{pH}$ & $\begin{array}{c}\mathrm{PCO}_{2} \\
(\mathrm{~mm} \mathrm{Hg})\end{array}$ & $\begin{array}{c}\mathrm{PO}_{2} \\
(\mathrm{~mm} \mathrm{Hg})\end{array}$ & $\begin{array}{l}\mathrm{SO}_{2} \\
(\%)\end{array}$ & $\begin{array}{l}\mathrm{cHb}^{*} \\
(\mathrm{~g} / \mathrm{dl})\end{array}$ & $\begin{array}{c}\mathrm{LDF} \dagger \\
(\%)\end{array}$ & $\begin{array}{c}\text { LDF } \\
\text { variability } \ddagger \\
(\%)\end{array}$ \\
\hline \multicolumn{8}{|l|}{ Before hypoxia } \\
\hline Mean & 7.33 & 41.4 & 20.1 & 52.1 & 8.0 & 100 & 6.2 \\
\hline SEM & 0.01 & 1.7 & 1.0 & 3.1 & 0.2 & & 0.9 \\
\hline Range & $7.26-7.38$ & $38.5-51.2$ & $15.8-24.5$ & $40.7-67.0$ & $7.2-9.1$ & & $2.2-10.1$ \\
\hline \multicolumn{8}{|l|}{ During hypoxia } \\
\hline Mean & 7.31 & 41.0 & $11.3 \S$ & $21.2 \S$ & $9.2 \S$ & $93.1 \S$ & $4.3 \S$ \\
\hline SEM & 0.02 & 3.0 & 0.3 & 1.2 & 0.3 & 0.7 & 0.4 \\
\hline Range & $7.22-7.42$ & $31.7-56.6$ & $10.4-12.6$ & $16.3-25.3$ & $7.7-10.2$ & $89.6-97.1$ & $2.3-8.9$ \\
\hline \multicolumn{8}{|c|}{ First $20 \mathrm{~min}$ after hypoxia } \\
\hline Mean & $7.28 \S$ & 41.9 & 19.2 & $44.9 \S$ & $8.5 \S$ & $92.5 \S$ & 5.5 \\
\hline SEM & 0.02 & 1.7 & 0.9 & 2.4 & 0.2 & 1.8 & 0.8 \\
\hline Range & $7.17-7.34$ & $36.7-48.7$ & $15.5-24.6$ & $34.6-54.1$ & $7.2-9.5$ & $80.7-99.3$ & $2.4-8.1$ \\
\hline \multicolumn{8}{|l|}{$\begin{array}{l}\text { Second } 20 \text { min after } \\
\text { hypoxia }\end{array}$} \\
\hline Mean & 7.33 & 38.6 & $18.1 \S$ & $46.3 \S$ & 7.8 & 96.9 & 5.5 \\
\hline SEM & 0.01 & 2.4 & 0.8 & 2.4 & 0.3 & 1.5 & 0.6 \\
\hline Range & $7.28-7.39$ & $33.3-51.0$ & $14.0-20.0$ & $36.0-55.7$ & $7.1-9.1$ & $88.3-104.6$ & $3.7-9.3$ \\
\hline
\end{tabular}

* Hemoglobin concentration.

$\dagger$ The LDF index is presented as \% of the LDF value in the period before hypoxia.

$\ddagger$ LDF variability is the RMS value of the difference between the original LDF signal and the averaged signal, obtained by using a moving window of $84 \mathrm{~s}$.

$\S$ Significantly different from control value before hypoxemia $(p<0.05)$.

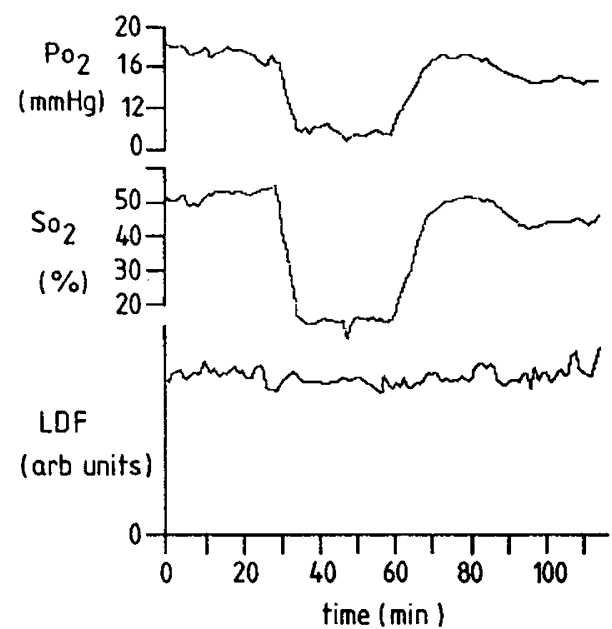

Fig. 1. Example of the course of fetal scalp blood flow (LDF) during hypoxemia as measured by the laser Doppler technique. Fetal carotid $\mathrm{PO}_{2}$ and $\mathrm{SO}_{2}$ were continuously measured in an external flow-through cuvette.

returned to the prehypoxic value. Thus, the LDF index recovered only in one experiment in the first and in three experiments in the second 20-min period after hypoxemia.

As shown in Table 1 (LDF variability), the spontaneous variations in the LDF signal decreased during hypoxia. However, in two experiments in two different animals there was an increase in the variability of the LDF signal during hypoxia.

Nonlabor uterine contractions, recorded by uterine EMG and/ or by intrauterine pressure, were present during the experimental procedure in all animals studied. No significant differences could be demonstrated between the control period prior to hypoxia, the period of hypoxia, and the posthypoxic recovery period regarding the fraction of time spent during contractions in every period.

\section{DISCUSSION}

The results of the present study indicate that red blood cell flow in scalp tissue, as measured by the laser Doppler technique, is slightly but consistently reduced during moderate hypoxemia in fetal lambs of 125 to 135 days of gestation. The observed average decrease in scalp LDF index of $6.9 \%$ can partly be ascribed to the direct influence of the fall in oxygen saturation on the absorptivity of hemoglobin during hypoxemia. A remarkable finding was the slow recovery of fetal scalp blood flow in the $40 \mathrm{~min}$ after hypoxemia.

Previous work with the laser Doppler method in acute experiments in fetal lambs (16) showed a considerable decrease in fetal scalp blood flow during hypoxemia, amounting to more than $60 \%$. This much more pronounced effect on scalp blood flow in the acute experiment might be partly explained by the influence of anesthesia on the fetal circulation. This seems the more likely because of the almost complete lack of spontaneous fluctuations in fetal scalp blood flow in those experiments. As shown in Figure 1 considerable spontaneous fluctuations in laser Doppler blood flow were measured in the scalp of the chronically catheterized sheep fetus. Similar fluctuations have been described in microcirculatory red blood cell flow in the skin of humans and in the rat mesentery (17-19). This phenomenon of spontaneous fluctuations in tissue blood flow is presumably caused by vasomotion, which is an intrinsic activity of the vascular smooth muscle, modulated by local chemical factors, changes in blood pressure, and changes in autonomous nervous system activity (17).

Comparison of our findings with data from the literature is difficult for two reasons. First, no data on fetal scalp blood flow during hypoxemia have been reported so far and second, to our knowledge, this is the first report on the application of the laser Doppler method in a chronic experiment in the fetal lamb. Most studies on tissue blood flow in the fetus have been carried out with microspheres. Cohn et al. (1), using the microsphere technique, reported a $30 \%$ decrease in fetal carcass blood flow (skin, muscle, and bone tissue) at a level of hypoxemia comparable to that in our study. In that study carcass blood flow was reduced 
by $70 \%$ when a concomitant acidemia occurred. Others, also using microspheres, have reported a sharp decrease in fetal carcass blood flow when the arterial oxygen content was less than $2.5 \mathrm{mmol} / \mathrm{liter}$, which corresponds with an oxygen saturation of approximately $40 \%$ (2).

With the usual diameter of the microspheres of $15 \mu \mathrm{m}$ used in those studies, mainly capillary blood flow is measured. The laser Doppler method provides essentially different information, because the recorded signal depends on the velocity as well as the number of moving red blood cells in a tissue sample of approximately $1 \mathrm{~mm}^{3}(7,11,15)$. Consequently, the measurement of red blood cell flow using the laser Doppler technique is not restricted to the capillaries, but also includes pre- and postcapillary vessels and, if present, arteriovenous anastomoses in the tissue sample.

Theoretically, the influence of the increased hematocrit on the LDF index is quite complex. The increase in the number of red blood cells in the microvascular bed of the fetal scalp will result in an increase in the laser Doppler signal. On the other hand, the raised hematocrit will also result in an increased whole blood viscosity, thereby decreasing red blood cell velocities. However, no data are available on the actual influence of changes in hematocrit on the LDF index, in vivo.

There have been a few studies comparing the LDF method with other tissue blood flow measuring techniques in adult humans and animals. Stern et al. (20), comparing the LDF method with the method using radiolabeled microspheres in the rat kidney, found proportionality between the results of the two methods during aortic constriction. Using Xenon clearance in another study, Stern et al. (15) reported a linear relation between LDF and Xenon clearance $(r=0.88)$. Others have compared the laser Doppler technique with the Xenon clearance technique and with venous occlusion plethysmography in the human forearm $(13,21)$. They too have reported linear relations $(r=0.88$ and $>0.9$, respectively).

A recent clinical study during labor (9) has demonstrated a dramatic reduction in fetal scalp blood flow, measured by the laser Doppler technique, presumably caused by mechanical factors such as local pressure and the "tonsure effect" (22). In that study, an average decrease in fetal scalp LDF index of more than $50 \%$ was found toward the end of the first stage of labor.

A previous study on the effect of mechanical pressure on the fetal scalp in the acute sheep experiment showed that a ring-like pressure, simulating the "tonsure effect," could reduce skin blood flow in the scalp surrounded by this ring considerably (23). In that study, scalp blood flow as measured with the Xenon clearance technique, was reduced by more than $50 \%$ when a rubber ring was applied to the skin with a pressure of $20-30 \mathrm{~mm} \mathrm{Hg}$.

The results of the present investigation indicate that the influence of moderate hypoxemia on fetal scalp red blood cell flow as measured by the laser Doppler technique is small, certainly when compared to the considerable reduction in fetal scalp blood flow caused by increased pressure on the fetal scalp.

Acknowledgments. The authors thank Prof. H. J. Huisjes, for reviewing the manuscript, Bram Posma, Bouke Woudstra, Ronald Zijlstra, Albert Evenhuis, Pieter Heida, Jelle Oord, Romke de Vries and Ben de Wolf for their invaluable assistance, and Jar Elstrodt for the anesthesia. We appreciate the help received from Marja de Haan and Jacob Pleiter in preparing the manuscript. We are indebted to Bristol-Meyers, Glaxo, Parke-Davis and Pharbil for kindly providing the antibiotics and anesthetics.

\section{REFERENCES}

1. Cohn HE, Sachs EJ, Heymann MA, Rudolph AM 1974 Cardiovascular responses to hypoxemia and acidemia in fetal lambs. Am $\mathrm{J}$ Obstet Gynecol 120:817-824

2. Peeters LLH 1978 Fetal blood flow at various levels of oxygen. Thesis, University of Nijmegen, The Netherlands

3. Rudolph AM, Heyman MA 1967 The circulation of the fetus in utero. Methods for studying distribution of blood flow, cardiac output and organ blood flow. Circ Res 21:163-184

4. Aarnoudse JG, Oeseburg B, Kwant G, Zwart A, Zijlstra WG, Huisjes HJ 1981 Influence of variations in $\mathrm{pH}$ and $\mathrm{PCO}_{2}$ on scalp tissue oxygen tension and carotid arterial oxygen tension in the fetal lamb. Biol Neonate 40:252-263

5. Buckberg GD, Luck JC, Payne DB, Hofman JIE, Archie JP, Fixler DE 1971 Some sources of error in measuring regional blood flow with radioactive microspheres. J Appl Physiol 31:598-604

6. Heymann MA, Payne BD, Hoffman JIE, Rudolph AM 1977 Blood flow measurement with radionuclide-labeled particles. Progr Cardiovasc Dis 20:55-79

7. Bonner R, Nossal R 1981 Model for laser Doppler measurement of blood flow in tissue. Appl Optics 20:2097-2107

8. Nilsson GE, Tenland T, Öberg PA 1980 A new instrument for continuous measurement of tissue blood flow by light beating spectroscopy. IEEE Trans Biomed Eng 27:12-19

9. Smits TM, Aarnoudse JG 1984 Variability of fetal scalp blood flow during labour. Continuous transcutaneous measurement by the laser Doppler technique. Br J Obstet Gynaecol 91:524-531

10. Stern MD 1975 In vivo evaluation of microcirculation by coherent light scattering. Nature 254:56-58

11. Watkins D, Holloway GA 1978 An instrument to measure cutaneous blood flow using the Doppler shift of laser light. IEEE Trans Biomed Eng 25:2833

12. Wunderlich RW, Folger RL, Giddon DB, Ware BR 1980 Laser Doppler blood flow meter and optical plethysmograph. Rev Sci Instr 51:1258-1262

13. Holloway GA, Watkins DW 1977 Laser Doppler measurement of cutaneous blood flow. J Invest Dermatol 69:306-309

14. Nilsson GE, Tenland TE, Oberg PA 1980 Evaluation of a laser Doppler flowmeter for measurement of tissue blood flow. IEEE Trans Biomed Eng 27:597-604

15. Stern MD, Lappe DL, Bowen PD, Chimosky JE, Holloway GA, Keiser HR Bowman LR 1977 Continuous measurement of tissue blood flow by laser Doppler spectroscopy. Am J Physiol 232:H441-H448

16. Smits TM, Cornel M, Aarnoudse JG, Oeseburg B, Kwant G, Zijlstra WG 1983 Transcutaneous laser Doppler flow (LDF) measurement of the fetal scalp at various oxygen levels in the sheep. Eur J Obstet Gynecol Repr Biol 15:156

17. Fagrell B, Fronek A, Intaglietta M 1977 A microscope-television system for studying flow velocity in human skin capillaries. Am J Physiol 233:H318$\mathrm{H} 321$

18. Johnson PC, Blaschke J, Benton KS, Dial JH (1973) Influence of flow variations on capillary hematocrit in mesentery. Am J Physiol 221:105-112

19. Salerud G, Nilsson GE, Tenland T, Öberg PA 1983 Rhythmic vasomotion in human skin studied by laser Doppler flowmetry. Int J Microcirc 2:91-102

20. Stern MD, Bowen PD, Parma R, Osgood RW, Bowman RL, Stein JH 1979 Measurement of renal cortical and medullary blood flow by laser Doppler spectroscopy in the rat. Am J Physiol 5:F80-F87

21. Johnson JM, Taylor WF, Shepherd AP, Park MK 1984 Laser Doppler measurement of skin blood flow: Comparison with plethysmography. J Appl Physiol 56:798-803

22. O'Connor MC, Hytten FE, Zanelli GD 1979 Is the fetus "scalped" during labour? Lancet 2:947-949

23. Aarnoudse JG, Crawley JCW, Flecknell PA, Hytten FE 1983 Scalp blood flow measured by the xenon clearance technique and transcutaneous $\mathrm{PO}_{2}$ in the fetal lamb. Pediatr Res 17:982-985 